\title{
Heats of formation of platonic hydrocarbon cages by means of high-level thermochemical procedures
}

\author{
Amir Karton, ${ }^{1,}{ }^{*}$ Peter R. Schreiner, ${ }^{2}$ and Jan M. L. Martin ${ }^{3}$ \\ ${ }^{1}$ School of Chemistry and Biochemistry, The University of Western Australia, Perth, WA \\ 6009, Australia. \\ ${ }^{2}$ Institut für Organische Chemie, Justus-Liebig-Universität, Heinrich-Buff-Ring 58, 35392 \\ Giessen, Germany. \\ ${ }^{3}$ Department of Organic Chemistry, Weizmann Institute of Science, Rehovot, Israel.
}

\begin{abstract}
Hydrocarbon cages are key reference materials for the validation and parameterization of computationally cost-effective procedures such as density functional theory, semiempirical molecular orbital theory, and molecular mechanics. We obtain accurate total atomization energies (TAEs) and heats of formation $\left(\Delta_{f} H^{\circ}{ }_{298}\right)$ for platonic and prismatic hydrocarbon cages by means of the $\mathrm{W} n$-F12 explicitly correlated thermochemical protocols. We consider the following kinetically stable $(\mathrm{CH})_{n}$ polycyclic hydrocarbon cages: (i) platonic hydrocarbons (tetrahedrane, cubane, and dodecahedrane), (ii) prismatic hydrocarbons (triprismane, cubane, and pentaprismane), and (iii) one truncated tetrahedrane (octahedrane). Our best theoretical heat of formation for cubane (144.8 kcal mol$\left.{ }^{-1}\right)$ suggests that the experimental value adopted by the NIST thermochemical database $\left(142.7 \pm 1.2 \mathrm{kcal} \mathrm{mol}^{-1}\right)$ should be revised upwards by $\sim 2 \mathrm{kcal} \mathrm{mol}^{-1}$. Our best heat of formation for dodecahedrane $\left(20.2 \mathrm{kcal} \mathrm{mol}^{-1}\right)$ suggests that the semi-experimental value $\left(22.4 \pm 1 \mathrm{kcal} \mathrm{mol}^{-1}\right)$ should be revised downward by $\sim 2 \mathrm{kcal} \mathrm{mol}^{-1}$. We use our benchmark Wn-F12 TAEs to evaluate the performance of a variety of computationally less demanding composite thermochemical procedures. These include the Gaussian- $n(\mathrm{G} n)$ and the complete basis set (CBS) methods. The CBS-QB3 and CBS-APNO procedures show relatively poor performance with rootmean-squared deviations (RMSDs) of 4.2 and $2.5 \mathrm{kcal} \mathrm{mol}^{-1}$, respectively. The best performers of the $\mathrm{G} n$ procedures are G4 and G3(MP2)B3 (RMSD $=0.5$ and $0.6 \mathrm{kcal} \mathrm{mol}^{-1}$, respectively), whilst the worst performers are G3 and G4(MP2)-6X (RMSD $=2.1$ and 2.9 $\mathrm{kcal} \mathrm{mol}{ }^{-1}$, respectively). Isodesmic and even homodesmotic reactions involving these species are surprisingly challenging targets for DFT computations.
\end{abstract}

Keywords: Computational thermochemistry $\cdot \operatorname{CCSD}(\mathrm{T}) \cdot$ Explicitly correlated coupled cluster $\bullet$ Platonic hydrocarbon cages $\bullet$ Prismatic hydrocarbon cages 


\section{Introduction}

Platonic hydrocarbons - the hydrocarbon analogs of the platonic solids - attracted considerable attention due to the aesthetically pleasing symmetry of their hydrocarbon framework (1-3, Fig. 1). ${ }^{1,2}$ In fact, for a long time it was believed that these highly symmetric $(\mathrm{CH})_{n}$ hydrocarbon cages were purely hypothetical. For example, long before the platonic hydrocarbon dodecahedrane was synthesized, the Nobel laureate Gerhard Herzberg conjectured that "it is not likely that molecules of $I_{\mathrm{h}}$ symmetry will ever be found". 3 Nevertheless, dodecahedrane - an array of twelve cis-fused cyclopentane rings with $I_{\mathrm{h}}$ symmetry - was synthesized by Paquette and co-workers in 1982. ${ }^{4,5}$ Tetrahedrane and cubane - tetrahedral and cubic configurations of $\mathrm{CH}$ (methine) groups - are platonic hydrocarbons in which the bond angles around the carbon atoms deviate significantly from a tetrahedral geometry (namely, with $\angle \mathrm{C}-\mathrm{C}-\mathrm{C}$ angles of $60^{\circ}$ and $90^{\circ}$ degrees, respectively). These platonic hydrocarbons were believed to be impossible to synthesize due to their high angular strain energies. Nevertheless, cubane was first synthesized in 1964 by Eaton and Cole. ${ }^{6}$ Parent tetrahedrane has not been synthesized to date, however, its tetra-tert-butyl derivative was prepared by Maier et al. in $1978 .^{7}$

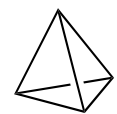

1

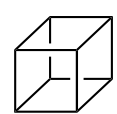

2

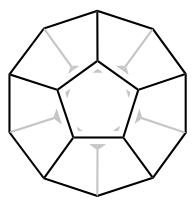

3

Figure 1. Platonic hydrocarbons: Tetrahedrane $\left(1, \mathrm{C}_{4} \mathrm{H}_{4}\right)$, cubane (2, $\left.\mathrm{C}_{8} \mathrm{H}_{8}\right)$, and dodecahedrane $\left(3, \mathrm{C}_{20} \mathrm{H}_{20}\right)$.

Prismanes are another class of $(\mathrm{CH})_{n}$ hydrocarbon cages, which are formed by two parallel regular $n$-gons connected by rectangular faces (2, Fig. 1; 4 and 5, Fig. 2). Prismanes are highly strained cage systems in which the bond angles around the carbon atoms deviate significantly from tetrahedral geometry. The prismanes that have been synthesized thus far $\left(2,{ }^{6} \quad 4^{8},{ }^{8} \text { and } \mathbf{5}\right)^{9}$ are characterized by $\angle \mathrm{C}-\mathrm{C}-\mathrm{C}$ angles of $60 / 900^{\circ}$ (triprismane, Ladenburg prismane, 4), 90॰(2), and 90/108 (pentaprismane, 5). These compounds (and many of their derivatives) are kinetically stable since their rearrangement and decomposition reactions are 
symmetry-forbidden. ${ }^{1}$ Despite its strain, octahedrane (6, Fig. 2) also is the most thermodynamically stable $(\mathrm{CH})_{12}$ hydrocarbon. ${ }^{10,11}$

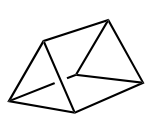

4

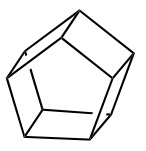

5

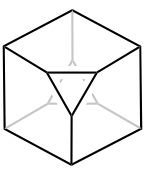

6

Figure 2. Additional $(\mathrm{CH})_{n}$ polycyclic hydrocarbon cages: Triprismane $\left(\mathbf{4}, \mathrm{C}_{6} \mathrm{H}_{6}\right)$, pentaprismane $\left(5, \mathrm{C}_{10} \mathrm{H}_{10}\right)$, and octahedrane $(\mathbf{6}$, $\mathrm{C}_{12} \mathrm{H}_{12}$ ).

In the present work, we obtain accurate theoretical heats of formation for the following $(\mathrm{CH})_{n}$ polycyclic hydrocarbon cages by means of the high-level W1-F12 and W2F12 theories: ${ }^{12}$

$>\quad$ Platonic hydrocarbons 1-3 (Fig. 1)

$>\quad$ Prismatic hydrocarbons 4 and 5 (Fig. 2)

$>\quad$ Truncated tetrahedrane: octahedrane (6) (Fig. 2)

The theoretical heats of formation for cubane and dodecahedrane deviate substantially (by 2$4 \mathrm{kcal} \mathrm{mol}{ }^{-1}$ ) from the reported experimental heats of formation. These discrepancies between theory and experiment suggest that re-examination of some of the experimental data may be in order. Interestingly, we also find an almost perfect linear correlation between the total atomization energies (TAEs) of the $(\mathrm{CH})_{n}$ hydrocarbon cages and the number of $\mathrm{CH}$ groups in these systems.

\section{Computational Methods}

In order to obtain reliable TAEs, computations have been carried out using the highlevel, ab initio Wn-F12 procedures ( $n=1$ and 2) with the Molpro 2012.1 program suite. $^{13,14}$ $\mathrm{W} 1-\mathrm{F} 12$ and W2-F12 theories ${ }^{12}$ (and their predecessors $\mathrm{W} 1$ and $\left.\mathrm{W} 2.2\right)^{15,16}$ represent layered extrapolations to the relativistic, all-electron $\operatorname{CCSD}(\mathrm{T}) / \mathrm{CBS}$ (coupled cluster with single, double, and quasiperturbative triple excitations complete-basis-set limit energy). These composite theories can achieve 'sub-chemical accuracy' for atomization reactions. ${ }^{12,15,16,17}$ For example, W1-F12 and W2-F12 theories are associated with root-mean-squared deviations (RMSDs) of 0.74 and $0.42 \mathrm{kcal} \mathrm{mol}^{-1}$ for a set of 137 very accurate atomization energies 
obtained at the full configuration interaction (FCI) infinite basis-set limit. ${ }^{12,17}$ The performance of these theories for systems containing only first-row elements (and $\mathrm{H}$ ) is of greater relevance to the present study. For the subset of 97 first-row atomization energies in the W4-11 database, W1-F12 shows significantly better performance with an RMSD of 0.45 kcal $\mathrm{mol}^{-1} \cdot{ }^{12,17}$ In the present work, we obtain TAEs at the W2-F12 level for the smaller $(\mathrm{CH})_{n}$ hydrocarbons $(n=4,6$, and 8$)$ and at the W1-F12 level for the larger hydrocarbons $(n$ $=10,12$, and 20). We note that the W1-F12 calculations for the largest system $(\mathrm{CH})_{20}$ strained our computational resources to the limit. In total, all the W1-F12 single-point energy calculations for $(\mathrm{CH})_{20}$ took $155 \mathrm{CPU}$ days on Intel Xeon E5-4650L cores (at $3.1 \mathrm{GHz}$ ) with 512 GB of RAM and 4 TB of solid-state disk.

W1-F12 and W2-F12 theories combine explicitly correlated F12 techniques ${ }^{18}$ with basis-set extrapolations in order to approximate the $\operatorname{CCSD}(\mathrm{T})$ infinite basis-set-limit energy. For the sake of making the article self-contained, we will briefly outline the various steps in these theories (for further details see Refs. 12 and 19). In W2-F12 the Hartree-Fock (HF) component is calculated with the VQZ-F12 basis set (where VnZ-F12 denotes the cc-pVnZF12 basis set of Peterson et al., ${ }^{20}$ which was specifically developed for explicitly correlated calculations). Note that the complementary auxiliary basis set (CABS) singles correction is included in the SCF energy. ${ }^{21,22}$ The valence CCSD-F12 correlation energy is extrapolated from the VTZ-F12 and VQZ-F12 basis sets, using the $E(L)=E_{\infty}+\mathrm{A} / L^{\alpha}$ two-point extrapolation formula, with $\alpha=5.94$. Optimal values for the geminal Slater exponents $(\beta)$ used in conjunction with the VnZ-F12 basis sets were taken from Ref. 23. The quasiperturbative triples, $(\mathrm{T})$, corrections are obtained from standard CCSD(T)/VTZ-F12 calculations (i.e., without inclusion of $\mathrm{F} 12$ terms) and scaled by the factor $f=0.987 \times \mathrm{E}^{\mathrm{MP} 2-}$ $\mathrm{F} 12 / \mathrm{E}^{\mathrm{MP} 2}$. This approach has been shown to accelerate the basis set convergence. ${ }^{12,24}$ In all of the explicitly correlated coupled cluster calculations the diagonal, fixed-amplitude 3C(FIX) ansatz $^{25,26,27,28}$ and the CCSD-F12b approximation are employed. ${ }^{24,29}$ The CCSD inner-shell contribution is calculated with the core-valence weighted correlation-consistent aug'-ccpwCVTZ basis set of Peterson and Dunning, ${ }^{30}$ whilst the $(\mathrm{T})$ inner-shell contribution is calculated with the cc-pwCVTZ(no f) basis set (where cc-pwCVTZ(no f) indicates the ccpwCVTZ basis set without the functions). The scalar relativistic contribution (in the secondorder Douglas-Kroll-Hess approximation) $)^{31,32}$ is obtained as the difference between nonrelativistic $\operatorname{CCSD}(\mathrm{T}) / \mathrm{A}^{\prime} \mathrm{VDZ}$ and relativistic $\operatorname{CCSD}(\mathrm{T}) / \mathrm{A}^{\prime} \mathrm{VDZ}-\mathrm{DK}$ calculations. ${ }^{33}$ The notation $\mathrm{A}^{\prime} \mathrm{V} n \mathrm{Z}$ indicates the combination of the standard correlation-consistent cc-p $\mathrm{V} n \mathrm{Z}$ basis sets on hydrogen, ${ }^{34}$ and the aug-cc-pVnZ basis sets on carbon. ${ }^{35}$ The atomic spin-orbit 
coupling terms are taken from the experimental fine structure, ${ }^{36}$ and the diagonal BornOppenheimer corrections (DBOCs) are calculated at the HF/cc-pVTZ level of theory using the CFOUR program suite. ${ }^{37,38}$ In the present work we additionally include a correlation correction to the DBOCs calculated at the CCSD/cc-pVDZ level.

The geometries and harmonic frequencies of all structures have been obtained at the B3LYP-D3BJ level of theory ${ }^{39,40,41}$ with the Weigend-Ahlrichs def2-TZVPP basis set. ${ }^{42}$ Throughout the manuscript, the suffix D3BJ refers to the inclusion of the D3 empirical dispersion corrections ${ }^{43,44}$ but with a Becke- Johnson ${ }^{45}$ damping function as recommended in Ref. 46. Harmonic vibrational analyses were performed at the same level as the optimizations in order to confirm that all structures are local minima. Zero-point vibrational energy (ZPVE), thermal enthalpy $\left(\mathrm{H}_{298}-\mathrm{H}_{0}\right)$, and entropy $(\mathrm{S})$ corrections were obtained from these frequencies within the RRHO (rigid rotor-harmonic oscillator) approximation. The ZPVE corrections have been scaled by 0.99 in accordance with a recent compilation of vibrational scale factors. ${ }^{19,47}$

The main difference between W1-F12 and W2-F12 theories is that W1-F12 uses smaller basis sets for extrapolating the HF, CCSD-F12, and (T) contributions. Specifically, the HF and CCSD-F12 contributions are extrapolated from the VDZ-F12 and VTZ-F12 basis-sets using the two-point extrapolation formula with $\alpha=5.00$ and 3.67, respectively. ${ }^{12,19}$ The $(\mathrm{T})$ valence correlation energy is obtained in the same way as in the original W1 theory, ${ }^{12,15}$ i.e., extrapolated from the $\mathrm{A}^{\prime} \mathrm{VDZ}$ and $\mathrm{A}^{\prime} \mathrm{VTZ}$ basis sets with $\alpha=3.22$.

Since W1-F12 and W2-F12 theories represent layered extrapolations to the allelectron $\operatorname{CCSD}(\mathrm{T})$ basis-set-limit energy, it is of interest to estimate whether the contributions from post-CCSD $(\mathrm{T})$ excitations are likely to be significant for the $(\mathrm{CH})_{n}$ hydrocarbon cages. The percentage of the total atomization energy accounted for by parenthetical connected triple excitations, \% $\mathrm{TAE}_{e}[(\mathrm{~T})]$, has been found to be a reliable energy-based diagnostic for the importance of post-CCSD $(\mathrm{T})$ contributions. It has been suggested that $\% \mathrm{TAE}_{e}[(\mathrm{~T})]<2 \%$ indicates systems that are dominated by dynamical correlation, while $2 \%<\% \operatorname{TAE}_{e}[(\mathrm{~T})]<$ $5 \%$ indicates systems that are characterized by mild nondynamical correlation. ${ }^{16,17,48}$ Table $\mathrm{S} 1$ (Supporting Information) gathers the $\% \mathrm{TAE}_{e}[(\mathrm{~T})]$ values for the hydrocarbon cages. The $\% \mathrm{TAE}_{e}[(\mathrm{~T})]$ values for these species span a narrow range between 1.9 (dodecahedrane) and 2.1 (tetrahedrane). These values suggest that these systems are dominated by dynamical correlation effects and that our bottom-of-the-well CCSD(T)/CBS TAEs should be well below $\sim 1 \mathrm{kcal} \mathrm{mol}^{-1}$ from the corresponding TAEs at the full configuration interaction (FCI) basis-set limit. ${ }^{16,17}$ 
We use our W1-F12 and W2-F12 benchmark TAEs to evaluate the performance of a range of more approximate composite procedures. Namely, the Gn-type methods: G4, ${ }^{49,50}$ G4(MP2), ${ }^{51} \mathrm{G} 4(\mathrm{MP} 2)-6 \mathrm{X},{ }^{52} \mathrm{G} 3,{ }^{53} \mathrm{G} 3(\mathrm{MP} 2),{ }^{54} \mathrm{G} 3 \mathrm{~B} 3,{ }^{55}$ and G3(MP2)B3,${ }^{55}$ and the complete basis set (CBS) methods: CBS-APNO ${ }^{56}$ and CBS-QB3. ${ }^{57}$ All geometry optimizations, frequency calculations, and the calculations for the $\mathrm{G} n$ and CBS procedures were performed using the Gaussian 09 program suite. ${ }^{58}$

A number of DFT methods were evaluated for their performance on bond separation reactions involving the platonic/prismatic hydrocarbon cages. The basis sets used were the Weigend-Ahlrichs ${ }^{42}$ def2-TZVPP and def2-QZVP basis sets; the functionals include the hybrid GGAs B3LYP and PBE0, ${ }^{59,60}$ the hybrid meta-GGA TPSS0, ${ }^{61,62,63}$ the highly empirical meta-GGAs M06 and M06-2X, ${ }^{64,65}$ the range-separated hybrids $\omega B$ 97X-D, ${ }^{66,67}$ M11, ${ }^{68}$ and $\omega \mathrm{B} 97 \mathrm{X}-\mathrm{V},{ }^{69}$ the double hybrids ${ }^{70} \mathrm{~B}^{2} \mathrm{PLYP}^{71}$ and B2GP-PLYP, ${ }^{72}$ and the spincomponent-scaled double hybrids DSD-PBEP86-D3BJ, ${ }^{73,74}$ DSD-PBEPBE-D3BJ, ${ }^{74}$ and DSD-PBEB95-D3BJ. ${ }^{74}$ Some of these density functional theory (DFT) calculations, particularly the double hybrid and $\omega \mathrm{B} 97 \mathrm{X}-\mathrm{V}$, were performed using a locally modified version of the ORCA program suite. ${ }^{75,76}$

\section{Results and Discussion}

Overview of the Wn-F12 total atomization energies. The component breakdown of the $\mathrm{W} n$-F12 TAEs and our resulting predicted heats of formation are gathered in Table 1. The magnitude of the HF component $(\Delta \mathrm{HF})$ can be very large. For example, at the W1-F12 level this component ranges from 571.02 (1) up to 3476.91 (3) $\mathrm{kcal} \mathrm{mol}^{-1}$. Nevertheless, for the three hydrocarbons for which we were able to obtain results at the W2-F12 level (1, 2, and 4), the differences between the $\mathrm{HF} / \mathrm{V}\{\mathrm{D}, \mathrm{T}\} \mathrm{Z}-\mathrm{F} 12$ (W1-F12) and HF/VQZ-F12 (W2-F12) components amount to less than $0.1 \mathrm{kcal} \mathrm{mol}^{-1}$ (Table 1). 
Table 1. Component breakdown of the W1-F12 and W2-F12 total atomization energies (TAEs) for tetrahedrane $\left(1, \mathrm{C}_{4} \mathrm{H}_{4}\right)$, triprismane $\left(4, \mathrm{C}_{6} \mathrm{H}_{6}\right)$, cubane $\left(2, \mathrm{C}_{8} \mathrm{H}_{8}\right)$, pentaprismane $\left(5, \mathrm{C}_{10} \mathrm{H}_{10}\right)$, octahedrane $\left(6, \mathrm{C}_{12} \mathrm{H}_{12}\right)$, and dodecahedrane $\left(3, \mathrm{C}_{20} \mathrm{H}_{20}\right)\left(\mathrm{kcal} \mathrm{mol}^{-1}\right)$

\begin{tabular}{|c|c|c|c|c|c|c|c|c|c|}
\hline & \multicolumn{2}{|c|}{1} & \multicolumn{2}{|c|}{4} & \multicolumn{2}{|c|}{2} & \multirow{2}{*}{$\begin{array}{c}\mathbf{5} \\
\text { W1-F12 }\end{array}$} & \multirow{2}{*}{$\begin{array}{c}\mathbf{6} \\
\text { W1-F12 }\end{array}$} & \multirow{2}{*}{$\begin{array}{c}\mathbf{3} \\
\mathrm{W} 1-\mathrm{F} 12\end{array}$} \\
\hline & W1-F12 & W2-F12 & W1-F12 & W2-F12 & W1-F12 & W2-F12 & & & \\
\hline$\Delta \mathrm{HF}$ & 571.02 & 571.03 & 917.35 & 917.39 & 1253.88 & 1253.98 & 1627.84 & 2036.94 & 3476.91 \\
\hline$\triangle \mathrm{CCSD}$ & 201.16 & 201.03 & 304.65 & 304.32 & 409.80 & 409.28 & 513.89 & 615.22 & 1034.02 \\
\hline$\Delta(\mathrm{T})$ & 16.85 & 16.68 & 25.67 & 25.52 & 34.45 & 34.24 & 43.51 & 52.03 & 87.50 \\
\hline$\Delta \mathrm{CV}^{a}$ & 5.09 & 5.16 & 6.96 & 7.10 & 8.86 & 9.10 & 11.21 & 14.10 & 23.03 \\
\hline$\Delta \operatorname{Rel}^{b}$ & -0.78 & -0.77 & -1.11 & -1.11 & -1.45 & -1.45 & -1.81 & -2.21 & -3.67 \\
\hline$\Delta \mathrm{S}-\mathrm{O}^{c}$ & -0.34 & $j$ & -0.51 & $j$ & -0.68 & $j$ & -0.85 & -1.02 & -1.69 \\
\hline$\Delta \mathrm{DBOC}^{d}$ & 0.15 & $j$ & 0.17 & $j$ & 0.18 & $j$ & 0.23 & 0.32 & 0.42 \\
\hline$\Delta \mathrm{ZPVE}^{e}$ & 36.96 & $j$ & 60.18 & $j$ & 82.82 & $j$ & 105.64 & 129.37 & 222.97 \\
\hline $\mathrm{TAE}_{e}^{f}$ & 794.11 & 793.90 & 1254.62 & 1254.32 & 1706.99 & 1706.59 & 2196.46 & 2718.29 & 4621.46 \\
\hline $\mathrm{TAE}_{0}{ }^{g}$ & 756.20 & 755.99 & 1192.99 & 1192.69 & 1622.22 & 1621.82 & 2088.38 & 2586.01 & 4393.55 \\
\hline$\Delta_{f} H_{0}{ }^{h}$ & 130.43 & 130.64 & 136.95 & 137.26 & 151.03 & 151.44 & 128.19 & 73.88 & 39.59 \\
\hline$\Delta_{f} H^{\circ}{ }_{298}^{h}$ & 128.36 & 128.57 & 132.53 & 132.84 & 144.38 & 144.78 & 119.42 & 63.08 & 20.18 \\
\hline$\Delta_{f} H^{\circ}{ }_{298}{ }^{i}$ & & 128.62 & & 132.92 & & 144.89 & 120.41 & 64.27 & 22.18 \\
\hline Expt. & & & & & 142. & $1.2^{k}$ & & & $22.4 \pm 1^{l}$ \\
\hline
\end{tabular}

${ }^{a}$ Core-valence correction. ${ }^{b}$ Scalar relativistic correction. ${ }^{c}$ First-order spin-orbit coupling. ${ }^{d}$ Diagonal Born-Oppenheimer correction. ${ }^{e}$ Zero-point vibrational energy correction. ${ }^{f}$ Nonrelativistic, all-electron, vibrationless CCSD(T) basis set limit TAEs (these values can be used for evaluation of DFT and ab initio procedures). ${ }^{g}$ Relativistic, all-electron, ZPVEinclusive $\operatorname{CCSD}(\mathrm{T})$ basis set limit TAEs at $0 \mathrm{~K}$ (for comparison with experiment and for the evaluation of composite ab initio procedures). ${ }^{h}$ Theoretical heats of formation at 0 and $298 \mathrm{~K}$. ${ }^{i}$ Heats of formation at $298 \mathrm{~K}$ obtained from isodesmic reaction (1) using ATcT $\Delta_{f} H^{\circ}{ }_{298}$ values for methane $(-17.814 \pm 0.014)$ and isobutene $(-32.352 \pm 0.096)$ and reaction energies from W2-F12 theory for the reactions involving $\mathrm{C}_{4} \mathrm{H}_{4}, \mathrm{C}_{6} \mathrm{H}_{6}$, and $\mathrm{C}_{8} \mathrm{H}_{8}$, and reaction energies from W1-F12 theory for the reactions involving $\mathrm{C}_{10} \mathrm{H}_{10}, \mathrm{C}_{12} \mathrm{H}_{12}$, and $\mathrm{C}_{20} \mathrm{H}_{20} .{ }^{j}$ From W1-F12 theory. ${ }^{k}$ Taken from the NIST WebBook (see text). ${ }^{l}$ Derived from the experimental $\Delta_{f} H^{\circ}{ }_{298}$ values for dodecahedrane and pagodane derivatives (see Ref. 77 for further details).

The magnitude of the valence CCSD correlation contribution ( $\triangle$ CCSD) to the TAEs is generally about one-third that of the $\Delta \mathrm{HF}$ component. For example, the $\triangle \mathrm{CCSD}$ component from W1-F12 theory extends from 201.16 (1) up to 1034.02 (3) $\mathrm{kcal} \mathrm{mol}^{-1}$. In contrast to the $\Delta \mathrm{HF}$ component, which is practically converged at the W1-F12 level, the differences between the $\triangle \mathrm{CCSD}$ contribution calculated at the CCSD-F12/V $\{\mathrm{D}, \mathrm{T}\} \mathrm{Z}-\mathrm{F} 12$ (W1-F12) and CCSDF12/V\{T,Q\}Z-F12 (W2-F12) level of theories can get quite significant for the larger hydrocarbon cages. Table 2 gives an overview of basis set convergence of the CCSD-F12 component of the total atomization energy. Extrapolating the CCSD-F12 energy from the $\mathrm{V}\{\mathrm{D}, \mathrm{T}\} \mathrm{Z}-\mathrm{F} 12$ basis set pair with an extrapolation exponent $(\alpha=3.38)$, which was optimized to minimize the RMSD over the 97 first-row systems in the W4-11 dataset, ${ }^{12,17}$ overshoots the W2-F12 value by $0.32(\mathbf{1}), 0.63(4)$, and $0.92(2) \mathrm{kcal} \mathrm{mol}^{-1}$. Using a larger extrapolation exponent of 3.67 (optimized over the entire W4-11 set of 137 first- and second-row systems) improves the situation, namely the deviations between W1-F12 and W2-F12 are reduced to 0.13 (1), 0.33 (4), and 0.52 (2) $\mathrm{kcal} \mathrm{mol}^{-1}$. On the other hand, using the extrapolation exponent optimized by Hill et al. ${ }^{23}$ over a smaller set of 14 absolute correlation energies $(\alpha=$ 
3.144), results in larger differences from W2-F12, namely 0.51 (1), 0.91 (4), and 1.31 (2) kcal $\mathrm{mol}^{-1}$.

Table 2. Overview of the valence CCSD-F12 correlation contribution to the TAEs for tetrahedrane $\left(1, \mathrm{C}_{4} \mathrm{H}_{4}\right)$, triprismane $\left(4, \mathrm{C}_{6} \mathrm{H}_{6}\right)$, cubane $\left(2, \mathrm{C}_{8} \mathrm{H}_{8}\right)$, pentaprismane $\left(\mathbf{5}, \mathrm{C}_{10} \mathrm{H}_{10}\right)$, octahedrane $\left(\mathbf{6}, \mathrm{C}_{12} \mathrm{H}_{12}\right)$, and dodecahedrane $\left(\mathbf{3}, \mathrm{C}_{20} \mathrm{H}_{20}\right)\left(\mathrm{kcal} \mathrm{mol}^{-1}\right)$

$\begin{array}{llcccccc}\text { Basis sets } & \alpha^{a} & \mathbf{1} & \mathbf{4} & \mathbf{2} & \mathbf{5} & \mathbf{6} & \mathbf{3} \\ \mathrm{V}\{\mathrm{D}, \mathrm{T}\} Z-F 12 & 3.14^{b} & 201.54 & 305.23 & 410.59 & 514.90 & 616.43 & 1036.08 \\ \mathrm{~V}\{\mathrm{D}, \mathrm{T}\} Z-F 12 & 3.38^{c} & 201.35 & 304.94 & 410.20 & 514.40 & 615.83 & 1035.06 \\ \mathrm{~V}\{\mathrm{D}, \mathrm{T}\} Z-F 12 & 3.67^{d} & 201.16 & 304.65 & 409.80 & 513.89 & 615.22 & 1034.02 \\ \text { V }\{\mathrm{T}, \mathrm{Q}\} Z-F 12 & 4.60^{b} & 201.15 & 304.48 & 409.50 & \text { N/A } & \text { N/A } & \text { N/A } \\ \text { V\{T,Q }\} Z-F 12 & 5.94^{d} & 201.03 & 304.32 & 409.28 & \text { N/A } & \text { N/A } & \text { N/A }\end{array}$

${ }^{a}$ Extrapolation exponent used in the two-point extrapolations. ${ }^{b}$ From Ref. 23, optimized over a set of 14 absolute CCSD correlation energies. ${ }^{c}$ Optimized to minimize the RMSD over 97 first-row atomization energies in the W4-11 dataset (see Refs. 12 and 17). ${ }^{d}$ Optimized to minimize the RMSD over 137 first- and second-row atomization energies in the W4-11 dataset (see Refs. 12, 17, and 19).

The valence $(\mathrm{T})$ correlation contributions $(\Delta(\mathrm{T})$, Table 1$)$ can be quite hefty, reaching up to $87.50 \mathrm{kcal} \mathrm{mol}^{-1}$ for $(\mathrm{CH})_{20}, 3$. For the smaller species, the differences between W1-F12 and W2-F12 amount to 0.17 (1), 0.15 (4), and 0.21 (2) $\mathrm{kcal} \mathrm{mol}^{-1}$; in all cases, W1-F12 overestimates the W2-F12 contribution. The core-valence $(\Delta \mathrm{CV})$ correlation contributions for the considered systems are also rather large, reaching up to $23.03 \mathrm{kcal} \mathrm{mol}^{-1}$ for 3 . The differences between W1-F12 and W2-F12 amount to 0.08 (1), 0.14 (4), and 0.24 (2) kcal $\mathrm{mol}^{-1}$. Here, however, the $\Delta \mathrm{CV}$ component from W1-F12 consistently underestimates the W2-F12 contribution. Overall, taking into account the $\Delta \mathrm{HF}, \Delta \mathrm{CCSD}, \Delta(\mathrm{T})$, and $\Delta \mathrm{CV}$ components the W1-F12 TAEs overestimate the W2-F12 values by 0.22 (1), 0.30 (4), and 0.39 (2) $\mathrm{kcal} \mathrm{mol}^{-1}$. This is due to some error cancelation between the $\Delta \mathrm{HF}$ and $\Delta \mathrm{CV}$ components (for which W1-F12 underestimates W2-F12) and the $\Delta$ CCSD and $\Delta(\mathrm{T})$ components (for which W1-F12 overestimates W2-F12).

The scalar relativistic ( $\Delta$ Rel) and first-order spin-orbit coupling $(\Delta \mathrm{S}-\mathrm{O})$ contributions both reduce the atomization energies by quite significant amounts. Specifically, $\Delta$ Rel ranges from -0.78 (1) to -3.67 (3) $\mathrm{kcal} \mathrm{mol}^{-1}$, and $\Delta \mathrm{S}-\mathrm{O}$ ranges between -0.34 (1) and -1.69 (3) kcal $\mathrm{mol}^{-1}$. This demonstrates once again that relativistic effects can becomes thermochemically significant for medium-sized hydrocarbons (see for example Refs. 12, 78, and 79).

Table 3 gives an overview of the Hartree-Fock and CCSD correlation contributions to the DBOC component of the TAEs. The DBOC contributions at the HF/cc-pVTZ level of theory range between 0.23 (1) and 0.78 (3) $\mathrm{kcal} \mathrm{mol}^{-1}$. We note the sizeable DBOC 
contribution for 3: for comparison, the DBOC contributions to the TAE (at the Hartree-Fock level) for other medium-sized organic systems are: 0.63 (corannulene, $\mathrm{C}_{20} \mathrm{H}_{10}$ ), ${ }^{80} 0.59$ (naphthacene, $\mathrm{C}_{18} \mathrm{H}_{12}$ ), ${ }^{81} 0.61$ (triphenylene, $\mathrm{C}_{18} \mathrm{H}_{12}$ ), ${ }^{80} 0.60$ (lysine, $\mathrm{C}_{6} \mathrm{H}_{14} \mathrm{~N}_{2} \mathrm{O}_{2}$ ), ${ }^{19}$ and 0.72 (arginine, $\left.\mathrm{C}_{6} \mathrm{H}_{14} \mathrm{~N}_{4} \mathrm{O}_{2}\right)^{19} \mathrm{kcal} \mathrm{mol}^{-1}$. It is also worth pointing out that the HF/cc-pVDZ level of theory gives essentially the same results at a much lower computational cost, namely the differences amount to less than $0.03 \mathrm{kcal} \mathrm{mol}^{-1}$ (Table 3). It has been previously found (see for example Refs. 19 and 78, and Refs. therein) that for systems with many hydrogen atoms correlation contributions to the DBOC will reduce the $\triangle \mathrm{DBOC}$ contribution to the TAE by up to $\sim 50 \%$. For the hydrocarbon cages the CCSD correlation correction to the DBOCs reduces the DBOC contribution to the TAEs by $35-46 \%$ (Table 3 ).

Table 3. Overview of the DBOC contribution to the TAEs for tetrahedrane $\left(\mathbf{1}, \mathrm{C}_{4} \mathrm{H}_{4}\right)$, triprismane $\left(4, \mathrm{C}_{6} \mathrm{H}_{6}\right)$, cubane $\left(2, \mathrm{C}_{8} \mathrm{H}_{8}\right)$, pentaprismane $(5$, $\left.\mathrm{C}_{10} \mathrm{H}_{10}\right)$, octahedrane $\left(6, \mathrm{C}_{12} \mathrm{H}_{12}\right)$, and dodecahedrane $\left(\mathbf{3}, \mathrm{C}_{20} \mathrm{H}_{20}\right)\left(\mathrm{kcal} \mathrm{mol}^{-}\right.$ $\left.{ }^{1}\right)$

\begin{tabular}{|c|c|c|c|c|c|c|}
\hline & 1 & 4 & 2 & 5 & 6 & 3 \\
\hline HF/cc-pVDZ & 0.23 & 0.29 & 0.34 & 0.43 & 0.55 & 0.81 \\
\hline HF/cc-pVTZ & 0.23 & 0.28 & 0.33 & 0.41 & 0.54 & 0.78 \\
\hline$\Delta \mathrm{CCSD} / \mathrm{cc}-\mathrm{pVDZ}{ }^{a}$ & -0.08 & -0.11 & -0.15 & -0.18 & -0.22 & -0.36 \\
\hline $\mathrm{Best}^{b}$ & 0.15 & 0.17 & 0.18 & 0.23 & 0.32 & 0.42 \\
\hline
\end{tabular}

Comparison of the Wn-F12 heats of formation with available experimental data. Our best total atomization energies at $0 \mathrm{~K}$ (TAE $\mathrm{TA}_{0}$, Table 1) are: 755.99 (1), 1192.69 (4), 1621.82 (2), 2088.38 (5), 2586.01 (6), and 4393.55 (3) $\mathrm{kcal} \mathrm{mol}^{-1}$. Using the ATcT atomic heats of formation at $0 \mathrm{~K}\left(\mathrm{H} 51.633 \pm 0.000\right.$ and C $\left.170.024 \pm 0.014 \mathrm{kcal} \mathrm{mol}^{-1}\right),{ }^{82,83,84}$ we convert our best $\mathrm{TAE}_{0}$ to heats of formation at $0 \mathrm{~K}\left(\Delta_{f} H_{0}\right.$, Table 1$)$. Consequently, the $\Delta_{f} H_{0}$ values are converted to heats of formation at $298 \mathrm{~K}\left(\Delta_{f} H^{\circ}{ }_{298}\right)$ using the CODATA enthalpy functions $\left(H_{298}-H_{0}\right)$ for the elemental reference states $\left(\mathrm{H}_{2}(\mathrm{~g})=2.024 \pm 0.000\right.$ and $\mathrm{C}(\mathrm{cr}$,graphite $)=$ $\left.0.251 \pm 0.005 \mathrm{kcal} \mathrm{mol}^{-1}\right)^{85}$ and the enthalpy functions for the $(\mathrm{CH})_{n}$ species are obtained (within the rigid-rotor harmonic oscillator approximation) from the B3LYP-D3BJ/Def2TZVPP geometries and harmonic frequencies. Our best Wn-F12 $\Delta_{f} H^{\circ}{ }_{298}$ values are: 128.57 (1), 132.84 (4), 144.78 (2), 119.42 (5), 63.08 (6), and 20.18 (3) kcal mol ${ }^{-1}$. We note that, while the present manuscript was in the final stages of preparation, Agapito et al. reported a W1-F12 $\Delta_{f} H^{\circ}{ }_{298}$ of $144.2 \mathrm{kcal} \mathrm{mol}^{-1}$ for $(2) .{ }^{86}$ We also note that Ref. 86 provides an excellent review of the previous experimental and theoretical works on the heat of formation of 
cubane. The W1-F12 value of Agapito et al. is in excellent agreement with our own W1-F12 value of $144.38 \mathrm{kcal} \mathrm{mol}^{-1}$; the residual difference of about $0.2 \mathrm{kcal} \mathrm{mol}^{-1}$ can be partially attributed to the slightly smaller scaling factor used in that work for the ZPVE ( 0.985 from the original W1 paper $^{15}$ instead of 0.99 from Ref. 47). While a difference of 0.005 in the ZPVE scaling factor would be insignificant compared for small molecules, it was found in Ref. 19 to lead to nontrivial systematic errors for systems the size of arginine.

Soon after the first synthesis of $\mathbf{2}^{6}$ the enthalpy of formation of crystalline $\mathbf{2}$ and the enthalpy of sublimation were measured to be $129.5 \pm 0.8$ and $19.2 \pm 0.4 \mathrm{kcal} \mathrm{mol}^{-1}$, respectively. ${ }^{87}$ These result in a gas-phase heat of formation at $298 \mathrm{~K}\left(\Delta_{f} H^{\circ}{ }_{298}\right)$ of $148.7 \pm 1$ $\mathrm{kcal} \mathrm{mol}^{-1}$. This heat of formation is identical to the value estimated from Benson's group additivity method, ${ }^{88}$ and is higher by almost $4 \mathrm{kcal} \mathrm{mol}^{-1}$ than our W2-F12 value of 144.78 $\mathrm{kcal} \mathrm{mol}^{-1}$. Bashir-Hashemi et al. re-measured the sublimation enthalpy of $2,{ }^{89,90}$ and reported a value of $13.2 \pm 0.5 \mathrm{kcal} \mathrm{mol}^{-1}$, which is smaller than the above value by as much as $6 \mathrm{kcal}$ $\mathrm{mol}^{-1}$ (The smaller sublimation enthalpy is in excellent agreement with the value of $13.1 \pm$ $0.5 \mathrm{kcal} \mathrm{mol}^{-1}$ recently reported by Chickos). ${ }^{91}$ Using this corrected enthalpy of sublimation we obtain an experimental $\Delta_{f} H^{\circ}{ }_{298}$ value of $142.7 \pm 1.2 \mathrm{kcal} \mathrm{mol}^{-1}$. This value, which was adopted by the NIST thermochemical database, ${ }^{92}$ is $2.08 \mathrm{kcal} \mathrm{mol}^{-1}$ lower than our W2-F12 value. Assigning a conservative error bar of $1 \mathrm{kcal} \mathrm{mol}^{-1}$ to our W2-F12 value, to account for potential issues with the scaled harmonic ZPVE, the discrepancy between theory and experiment is just below the sum of the respective uncertainties. Nevertheless, it should be pointed out that the error bar of the experimental enthalpy of formation of crystalline 2 may be larger than the assigned value of $0.8 \mathrm{kcal} \mathrm{mol}^{-1}$ due to the use of an unspecified correction in the conversion of the combustion measurements to a crystalline enthalpy of formation. ${ }^{87,89}$ Finally, as a 'sanity check' on the theoretical and experimental gas-phase $\Delta_{f} H^{\circ}{ }_{298}$ values for 2 we consider the following isodesmic reaction:

$$
(\mathrm{CH})_{n}+n \mathrm{CH}_{4} \longrightarrow \frac{n}{2} \text { isobutane }
$$

for which ATcT $\Delta_{f} H^{\circ}{ }_{298}$ values are available for all the species apart from 2. Using the W2F12 reaction enthalpy at $298 \mathrm{~K}\left(-131.78 \mathrm{kcal} \mathrm{mol}^{-1}\right)$ and the ATcT $\Delta_{f} H^{\circ}{ }_{298}$ values $(-17.814 \pm$ 0.014 for methane, and $-32.352 \pm 0.096 \mathrm{kcal} \mathrm{mol}^{-1}$ for isobutene) we obtain a $\Delta_{f} H^{\circ}{ }_{298}$ value for 2 of $144.89 \mathrm{kcal} \mathrm{mol}^{-1}$ in close agreement with our theoretical W2-F12 value. 
A 'semi-experimental' heat of formation of $\Delta_{f} H^{\circ}{ }_{298}=22.4 \pm 1 \mathrm{kcal} \mathrm{mol}^{-1}$ for 3 was derived by Beckhaus et al. ${ }^{77}$ from the experimental heats of formation for derivatives of $\mathbf{3}$ and pagodane. This value is higher by $2.22 \mathrm{kcal} \mathrm{mol}^{-1}$ than our best W1-F12 value. Again, this discrepancy between theory and experiment is only slightly above the sum of the respective uncertainties. However, our theoretical heat of formation suggests that the experimental value should be revised downwards.

\section{Linear correlation between the number of $\mathrm{CH}$ groups and the components of the total} atomization energies. Interestingly, we find an almost perfect linear correlation between all the components of the total atomization energies in Table $1(\Delta \mathrm{HF}, \Delta \mathrm{CCSD}, \Delta(\mathrm{T}), \Delta \mathrm{CV}, \Delta \mathrm{Rel}$, $\triangle \mathrm{DBOC}, \triangle \mathrm{S}-\mathrm{O}, \triangle \mathrm{ZPVE}, \mathrm{TAE}_{e}$, and $\left.\mathrm{TAE}_{0}\right)$ and the number of $\mathrm{CH}$ groups in the $(\mathrm{CH})_{n}$ hydrocarbon cages. Table S2 of the Supporting Information gives the squared correlation coefficients $\left(\mathrm{R}^{2}\right)$ for all the components of the TAE. Suffice to say that, with the exception of the $\triangle \mathrm{DBOC}$ component for which $\mathrm{R}^{2}=0.9437$, all the components of the TAE are associated with $\mathrm{R}^{2} \geq 0.9996$. The final atomization energies $\left(\mathrm{TAE}_{e}\right.$ and $\left.\mathrm{TAE}_{0}\right)$ are both associated with $\mathrm{R}^{2}=0.9998$. Figure 3 illustrates the linear correlation between the $\mathrm{TAE}_{0}$ and the number of $\mathrm{CH}$ groups in the considered $(\mathrm{CH})_{n}$ polycyclic hydrocarbon cages.

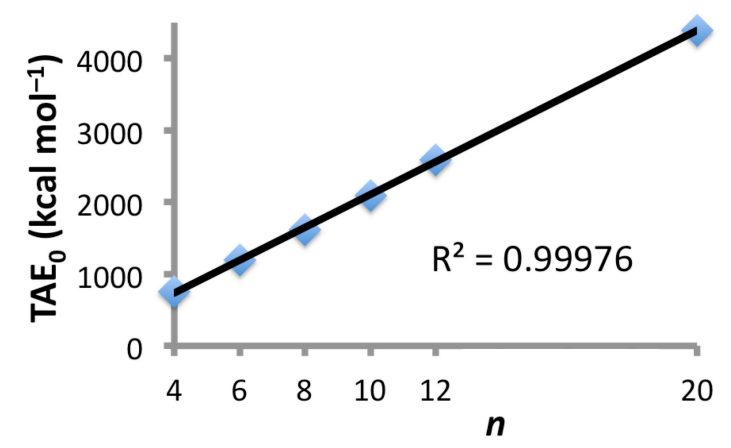

Figure 3. Linear correlation between the total atomization energies at $0 \mathrm{~K}\left(\mathrm{TAE}_{0}\right)$ and the number of $\mathrm{CH}$ groups in the $(\mathrm{CH})_{n}$ polycyclic hydrocarbon cages 1-6.

This linear relationship indicates that the platonic and prismatic hydrocarbons form a homologous series even though they involve different angular strain energies. For example, the strain energies involved in the considered polycyclic hydrocarbon cages could be estimated from the energy of the following homodesmotic reaction (see also below): ${ }^{1}$ 


$$
(\mathrm{CH})_{n}+\frac{3 n}{2} \mathrm{C}_{2} \mathrm{H}_{6} \longrightarrow n \text { isobutane }
$$

Using our best heats of formation $\left(\Delta_{f} H^{\circ}{ }_{298}\right.$, Table 1), we obtain the following reaction enthalpies at $298 \mathrm{~K}:-136.18$ (1), -144.24 (4), -159.99 (2), -139.55 (5), -87.24 (6), and $60.45(3) \mathrm{kcal} \mathrm{mol}^{-1}$. Cubane (2) is characterized by the highest strain energy $\left(E_{\mathrm{st}}=160.0\right.$ $\mathrm{kcal} \mathrm{mol}^{-1}$ ). The platonic/prismatic hydrocarbons $\mathbf{1}, \mathbf{4}$, and $\mathbf{5}$ are characterized by lower strain energies $\left(E_{\mathrm{st}}=136.2-144.2 \mathrm{kcal} \mathrm{mol}^{-1}\right)$. Octahedrane (6) displays a significantly lower strain energy $\left(E_{\mathrm{st}}=87.2 \mathrm{kcal} \mathrm{mol}^{-1}\right)$, and dodecahedrane (3) is associated with the lowest strain energy $\left(E_{\mathrm{st}}=60.5 \mathrm{kcal} \mathrm{mol}^{-1}\right)$. It is also instructive to compare the strain energies per $\mathrm{CH}$ group, these values are: -34.0 (1), -24.0 (4), -20.0 (2), -14.0 (5), -7.3 (6), and -3.0 (3) kcal $\mathrm{mol}^{-1}$. We note that for the hydrocarbon cages $(\mathrm{CH})_{n}(n=4-12)$ there is a reasonably high statistical correlation between the strain energy per $\mathrm{CH}$ group and the number of $\mathrm{CH}$ groups (with $\mathrm{R}^{2}=0.9827$ ). However, inclusion of the anomalous $(\mathrm{CH})_{20}$ system results in $\mathrm{R}^{2}=$ 0.8426 .

Performance of computationally economical composite procedures. Table 4 reports the deviations from our best Wn-F12 benchmark $\mathrm{TAE}_{0}$ for the $(\mathrm{CH})_{n}$ polycyclic hydrocarbon cages for a range of more approximate composite procedures (e.g., G4, G4(MP2), G4(MP2)6X, CBS-QB3, and CBS-APNO). We can see that the G3 method performs poorly with almost all deviations exceeding the 'chemical accuracy' threshold of $1 \mathrm{kcal} \mathrm{mol}^{-1}$. For three out of the six systems $\left(\mathbf{2}, \mathbf{4}\right.$, and 5) the deviations from $\mathrm{Wn}$-F12 theory exceed $2 \mathrm{kcal} \mathrm{mol}^{-1}$, and the overall RMSD is $2.1 \mathrm{kcal} \mathrm{mol}^{-1}$. The G3B3 variant of G3 in which the geometries and ZPVEs are calculated at the B3LYP/6-31G(d) level of theory (rather than MP2/6-31G(d) geometries and HF/6-31G(d) ZPVEs in G3) cuts the deviations by $0.6-1.0 \mathrm{kcal} \mathrm{mol}^{-1}$ and the overall RMSD to $1.4 \mathrm{kcal} \mathrm{mol}^{-1}$. However deviations of above $1 \mathrm{kcal} \mathrm{mol}^{-1}$ are still obtained for $\mathbf{1}, \mathbf{4}, \mathbf{2}$, and $\mathbf{5}$. Interestingly, the computationally more economical G3(MP2) procedure shows similar performance to G3B3 with an overall RMSD of $1.3 \mathrm{kcal} \mathrm{mol}^{-1}$. An even more striking result, however, is the performance of the G3(MP2)B3 variant of G3(MP2). Apart from 3 , for which a deviation of $1.2 \mathrm{kcal} \mathrm{mol}^{-1}$ is obtained, all the deviations are below the 'chemical accuracy' threshold, and the overall RMSD is only $0.6 \mathrm{kcal} \mathrm{mol}^{-1}$.

Moving on to the performance of the Gaussian-4 family, the G4 method shows excellent performance with all deviations below $0.8 \mathrm{kcal} \mathrm{mol}^{-1}$, and an overall RMSD of merely $0.5 \mathrm{kcal} \mathrm{mol}^{-1}$. We note that the $\mathrm{G} 4$ method puts in the best performance out of all the 
composite procedures. The G4(MP2) procedure, which is computationally more economical than G4, performs fairly well relative to its computational cost, with an overall RMSD of 0.9

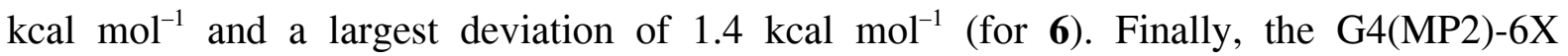
procedure, which usually shows similar performance to G4(MP2) for difficult reactions in which multiple bonds are being broken and formed, ${ }^{17,93}$ gives poor performance for the hydrocarbon cages. The overall RMSD is $2.9 \mathrm{kcal} \mathrm{mol}^{-1}$ and particularly large deviations of 3.6 and $5.4 \mathrm{kcal} \mathrm{mol}^{-1}$ are obtained for $\mathbf{3}$ and $\mathbf{6}$, respectively.

Table 4. Deviations for computationally economical composite procedures for the $\mathrm{TAE}_{0}$ of tetrahedrane $\left(1, \mathrm{C}_{4} \mathrm{H}_{4}\right)$, triprismane $\left(4, \mathrm{C}_{6} \mathrm{H}_{6}\right)$, cubane $\left(2, \mathrm{C}_{8} \mathrm{H}_{8}\right)$, pentaprismane $\left(\mathbf{5}, \mathrm{C}_{10} \mathrm{H}_{10}\right)$, octahedrane $\left(\mathbf{6}, \mathrm{C}_{12} \mathrm{H}_{12}\right)$, and dodecahedrane $\left(\mathbf{3}, \mathrm{C}_{20} \mathrm{H}_{20}\right)$ $\left(\mathrm{kcal} \mathrm{mol}^{-1}\right)^{a, b}$

$\begin{array}{lccccccc} & \mathbf{1} & \mathbf{4} & \mathbf{2} & \mathbf{5} & \mathbf{6} & \mathbf{3} & \text { RMSD }^{c} \\ \text { G3 } & -1.80 & -2.61 & -2.71 & -2.73 & -1.17 & -0.82 & 2.12 \\ \text { G3B3 } & -1.23 & -1.94 & -1.72 & -1.76 & -0.43 & 0.17 & 1.39 \\ \text { G3(MP2) } & -0.57 & -1.46 & -1.63 & -1.90 & -0.67 & -1.06 & 1.31 \\ \text { G3(MP2)B3 } & 0.18 & -0.48 & -0.18 & -0.34 & 0.77 & 1.21 & 0.64 \\ \text { G4 } & 0.15 & -0.20 & -0.34 & -0.67 & 0.79 & 0.23 & 0.47 \\ \text { G4(MP2) } & 1.12 & 0.77 & 0.78 & 0.31 & 1.35 & 0.66 & 0.90 \\ \text { G4(MP2)-6X } & 0.85 & 1.06 & 1.50 & 1.69 & 3.64 & 5.43 & 2.88 \\ \text { CBS-QB3 } & -2.20 & -3.09 & -3.95 & -4.56 & -3.82 & -6.24 & 4.17 \\ \text { CBS-APNO } & 0.06 & 0.77 & 0.13 & 0.91 & 4.46 & 4.13 & 2.53\end{array}$

${ }^{a}$ Reference values are the best $\mathrm{TAE}_{0}$ values from Table 1 (i.e., from W2-F12 theory for 1, 4, and 2; and from W1-F12 theory for 5, 6, and 3). ${ }^{b}$ The tabulated values are $\mathrm{TAE}_{0}$ (given method)-TAE $0(\mathrm{~W} n-\mathrm{F} 12)$. ${ }^{c}$ RMSD over the six systems.

We now turn our attention to the CBS procedures. The computationally economical CBS-QB3 shows very poor performance with an overall RMSD of $4.2 \mathrm{kcal} \mathrm{mol}^{-1}$. We note that in contrast to the general tendency of this procedure to overestimate TAEs, ${ }^{17,93,94}$ here it tends to strongly underestimate the atomization energies. The CBS-APNO procedure shows good performance with deviations below the 'chemical accuracy' threshold for all the systems apart from octahedrane and dodecahedrane. However, for these two systems unacceptably large deviations of 4.5 and $4.1 \mathrm{kcal} \mathrm{mol}^{-1}$ are obtained.

Isodesmic and homodesmotic reactions at lower levels of theory. Wheeler et al. introduced the $\mathrm{RC}-n$ hierarchy of isodesmic and homodesmotic reactions for hydrocarbons; ${ }^{95,96}$ the Connectivity-Based Hierarchy (CBH) of Ramabhadran and Raghavachari represents a generalization of the same concept. ${ }^{97,98} \mathrm{RC}-1$ and $\mathrm{CBH}-0$ both 
correspond to Pople-style isogyric bond separation reactions. For the problem at hand, they work out to:

$$
(\mathrm{CH})_{n}+\frac{3 n}{2} \mathrm{H}_{2} \rightarrow n \mathrm{CH}_{4}
$$

RC-2 and CBH-1 correspond to isodesmic bond separation reactions (i.e., that preserve the number of bonds of each formal type). In the present case, they correspond to:

$$
(\mathrm{CH})_{n}+2 n \mathrm{CH}_{4} \rightarrow \frac{3 n}{2} \mathrm{C}_{2} \mathrm{H}_{6}
$$

The distinction between RC-3 (hypohomodesmotic) and RC-4 (homodesmotic) reactions is not applicable for the present problem owing to the absence of multiple bonds. RC-4 and $\mathrm{CBH}-2$ are equivalent here, both corresponding to equation (2) above. Note that this reaction preserves the number of carbons of each branching degree. Barić and Maksić, ${ }^{99}$ however, apply the label 'quasihomodesmotic' to reactions like (2) for severely strained cases like 2, as the strain engenders additional p-character in the $\mathrm{C}-\mathrm{C}$ bonds, leading to an effective imbalance in the number of $\mathrm{sp}^{3}$ carbons. For similar reasons, it appears (Table 5) that the hyperhomodesmotic reaction ( $\mathrm{RC}-5$ or $\mathrm{CBH}-3)$

$$
(\mathrm{CH})_{n}+2 n \text { isobutane } \rightarrow \frac{3 n}{2}(2,3 \text {-dimethylbutane })
$$

is probably better described as 'quasihyperhomodesmotic': despite formally preserving the numbers of $\mathrm{CH}_{3}-\mathrm{CH}_{2}, \mathrm{CH}_{3}-\mathrm{CH}<,-\mathrm{CH}_{2}-\mathrm{CH}_{2}-, \ldots$ the p-character of these bonds in fact undergoes considerable change.

Under normal circumstances, reaction energies along this hierarchy would exhibit ever faster convergence in the basis set and the electron correlation method. In the present case, however, the p-strain imbalance leads to a considerable slowdown in convergence. Still, as can be seen for the W1-F12 component breakdown in Table 5, the (T) contribution to the reaction energies for RC-4, Eq. (2), is much smaller than for RC-2, Eq. (4), which in turn is smaller still than that for RC-1, Eq. (3), which finally is still a huge improvement over raw total atomization energies (which one might term RC-0). RC-5 appears to be of very limited value in the present scenario. The SCF and CCSD valence correlation components drop precipitously from TAE/RC-0 to RC-1 (isogyric) to RC-2 (isodesmic), but do not appear to 
be significantly reduced beyond this point. The $\operatorname{CCSD}(\mathrm{T})-\mathrm{MP} 2$ difference still drops from RC-2 to RC-4 though. Core-valence correlation contributions are reduced dramatically from raw TAEs to RC-1, with more modest further reductions for RC-2 and RC-4.

Table 5. W1-F12 component breakdown of bond separation reaction energies $\left(\mathrm{kcal} \mathrm{mol}^{-1}\right)^{a}$

\begin{tabular}{|c|c|c|c|c|c|c|c|c|c|c|}
\hline & W1-F12 & $\mathrm{HF}$ & CCSD & $(\mathrm{T})$ & $\mathrm{CV}$ & W1-F12 & $\mathrm{HF}$ & CCSD & $(\mathrm{T})$ & $\mathrm{CV}$ \\
\hline \multicolumn{6}{|c|}{ RC-1, CBH-0 ${ }^{b}$} & \multicolumn{5}{|c|}{$\mathrm{RC}-2, \mathrm{CBH}-1^{c}$} \\
\hline ethane & 18.18 & 21.24 & -2.56 & -0.58 & 0.08 & & & & & \\
\hline propane & 34.20 & 41.58 & -6.12 & -1.38 & 0.14 & -2.16 & -0.90 & -1.00 & -0.23 & -0.02 \\
\hline isobutane & 48.67 & 61.69 & -10.76 & -2.44 & 0.19 & -5.88 & -2.03 & -3.08 & -0.71 & -0.05 \\
\hline diisopropyl & 80.90 & 106.18 & -20.89 & -4.69 & 0.31 & -10.02 & -0.02 & -8.09 & -1.82 & -0.09 \\
\hline$(\mathrm{CH})_{4}, \mathbf{1}$ & 230.55 & 252.05 & -16.16 & -5.15 & -0.19 & 121.45 & 124.61 & -0.80 & -1.70 & -0.67 \\
\hline$(\mathrm{CH})_{6}, 4$ & 282.36 & 317.26 & -27.16 & -8.12 & 0.40 & 118.72 & 126.10 & -4.12 & -2.95 & -0.32 \\
\hline$(\mathrm{CH})_{8}, 2$ & 342.33 & 392.26 & -39.81 & -11.05 & 0.95 & 124.14 & 137.38 & -9.09 & -4.15 & -0.01 \\
\hline$(\mathrm{CH})_{10}, \mathbf{5}$ & 365.20 & 429.84 & -51.40 & -14.26 & 1.05 & 92.46 & 111.24 & -13.00 & -5.63 & -0.15 \\
\hline$(\mathrm{CH})_{12}, 6$ & 355.70 & 432.28 & -60.23 & -16.93 & 0.61 & 28.40 & 49.96 & -14.15 & -6.58 & -0.83 \\
\hline \multirow[t]{2}{*}{$(\mathrm{CH})_{20}, 3$} & 501.85 & 638.45 & -109.04 & -29.00 & 1.49 & -43.64 & 1.25 & -32.24 & -11.75 & -0.91 \\
\hline & \multicolumn{3}{|c|}{$\mathrm{RC}-4, \mathrm{CBH}-2^{d}$} & & & \multicolumn{5}{|c|}{$\mathrm{RC}-5, \mathrm{CBH}-3^{e}$} \\
\hline diisopropyl & 1.74 & 4.04 & -1.93 & -0.39 & 0.01 & & & & & \\
\hline$(\mathrm{CH})_{4}, \mathbf{1}$ & 144.96 & 132.72 & 11.53 & 1.16 & -0.46 & 134.55 & 108.49 & 23.09 & 3.49 & -0.53 \\
\hline$(\mathrm{CH})_{6}, 4$ & 153.98 & 138.26 & 14.39 & 1.34 & -0.02 & 138.35 & 101.92 & 31.72 & 4.84 & -0.13 \\
\hline$(\mathrm{CH})_{8}, 2$ & 171.15 & 153.60 & 15.58 & 1.56 & 0.40 & 150.32 & 105.14 & 38.70 & 6.23 & 0.25 \\
\hline$(\mathrm{CH})_{10}, \mathbf{5}$ & 151.23 & 131.51 & 17.84 & 1.51 & 0.36 & 125.19 & 70.94 & 46.73 & 7.34 & 0.18 \\
\hline$(\mathrm{CH})_{12}, 6$ & 98.93 & 74.28 & 22.86 & 1.99 & -0.22 & 67.68 & 1.60 & 57.52 & 8.99 & -0.43 \\
\hline$(\mathrm{CH})_{20}, 3$ & 73.90 & 41.79 & 29.44 & 2.53 & 0.11 & 21.82 & -79.35 & 87.22 & 14.20 & -0.25 \\
\hline
\end{tabular}

${ }^{a}$ Nonrelativistic, clamped-nuclei reaction energy. ${ }^{b}$ Isogyric bond separation reactions, Eq. (3). ${ }^{c}$ Isodesmic bond separation reactions, Eq. (4). ${ }^{d}$ (Quasi)homodesmotic bond separation reactions, Eq. (2). ${ }^{e}($ Quasi)hyperhomodesmotic bond separation reactions, Eq. (5).

Let us now consider some more approximate methods. The RMSDs relative to the W1-F12 values are summarized in Table 6. As can be seen, basis set sensitivity for MP2 
drops precipitously from isogyric to isodesmic reactions, yet even for the isodesmic reaction the Weigend-Ahlrichs def2-TZVPP still is almost $1.5 \mathrm{kcal} \mathrm{mol}^{-1}$ RMS away from the basis set limit, compared to $0.9 \mathrm{kcal} \mathrm{mol}^{-1}$ for the homodesmotic reactions. For B3LYP, on the other hand, def2-TZVPP is adequately converged even for the isogyric reactions, and definitely for the isodesmic and homodesmotic ones. The same applies, to a somewhat lesser extent, to the DSD-PBEP86 double hybrid functional. We have thus chosen def2-TZVPP as the basis set for the DFT evaluations.

Table 6. RMSD (in $\mathrm{kcal} \mathrm{mol}^{-1}$ ) for bond separation reactions from the W1F12 nonrelativistic, clamped-nuclei reference values

\begin{tabular}{|c|c|c|c|c|}
\hline $\operatorname{Method}^{a}$ & $\begin{array}{l}\text { RC-0 } \\
\text { TAE }\end{array}$ & $\begin{array}{c}\text { RC-1, CBH-0 } \\
\text { isogyric }\end{array}$ & $\begin{array}{l}\mathrm{RC}-2, \mathrm{CBH}-1 \\
\text { isodesmic }\end{array}$ & $\begin{array}{r}\text { RC-4, CBH-2 } \\
\text { homodesmotic }\end{array}$ \\
\hline$\omega B 97 X-D 3$ & 3.8 & 25.3 & 10.9 & 6.6 \\
\hline$\omega B 97 X-V$ & 8.7 & 7.3 & 5.2 & 4.9 \\
\hline B3LYP-D3BJ & 16.3 & 23.1 & 9.4 & 3.3 \\
\hline B3LYP-D3BJ ${ }^{b}$ & 16.8 & 22.9 & 9.1 & 3.3 \\
\hline B3LYP-NL ${ }^{b}$ & 4.5 & 12.7 & 6.8 & 2.9 \\
\hline $\mathrm{B} 3 \mathrm{LYP}^{b}$ & 58.7 & 45.0 & 14.4 & 23.1 \\
\hline B2PLYP-D3BJ & 23.2 & 16.8 & 3.9 & 3.5 \\
\hline B2GPPLYP-D3BJ & 23.3 & 16.3 & 3.6 & 2.3 \\
\hline PBE0-D3BJ & 49.0 & 13.9 & 8.8 & 3.7 \\
\hline TPSS0-D3BJ & 3.5 & 7.1 & 6.5 & 11.5 \\
\hline M06-2X & 9.9 & 8.6 & 15.3 & 8.9 \\
\hline M06 & 17.9 & 29.4 & 11.7 & 11.5 \\
\hline M11 & 19.9 & 32.1 & 9.7 & 13.1 \\
\hline DSD-PBEPBE-D3BJ & 1.5 & 0.7 & 1.0 & 3.6 \\
\hline DSD-PBEB95-D3BJ & 8.3 & 3.3 & 4.4 & 9.4 \\
\hline DSD-PBEP86-D3BJ & 15.0 & 4.7 & 3.4 & 0.9 \\
\hline DSD-PBEP86-D3BJ ${ }^{b}$ & 2.0 & 4.1 & 3.6 & 1.3 \\
\hline MP2 & 3.4 & 13.4 & 11.1 & 2.9 \\
\hline $\mathrm{MP}^{b}$ & 35.3 & 14.6 & 10.3 & 2.2 \\
\hline MP2-F12/VTZ-F12 & 59.2 & 19.4 & 9.8 & 2.1 \\
\hline MP2-F12/VQZ-F12 & 59.6 & 19.5 & 9.7 & 2.1 \\
\hline CBS-QB3 & 4.2 & 16.2 & 5.8 & 2.8 \\
\hline CBS-APNO & 2.5 & 1.8 & 2.2 & 1.6 \\
\hline
\end{tabular}

Clearly, the present problem is "a tough nut to crack" for conventional DFT functionals: while B3LYP and PBE0 can get RMSDs in the $3 \mathrm{kcal} \mathrm{mol}^{-1}$ range for the homodesmotic reactions, they go up to the $9 \mathrm{kcal} \mathrm{mol}^{-1}$ range for the isodesmic reactions and 
still higher for the isogyric ones. Highly empirical functionals like M06, M06-2X, and even the range-separated hybrids M11 and $\omega$ B97X-D3 yield RMSDs of 9-13 kcal mol ${ }^{-1}$ even for the homodesmotic reactions, and similar or poorer errors for the isodesmic ones.

Comparison of the B3LYP values with and without D3BJ reveals the great importance of dispersion corrections. In fact, replacing the molecular mechanics-like D3BJ correction with the Vydrov-Van Voorhis nonlocal dispersion functional ${ }^{100,101}$ (i.e., B3LYPNL) leads to a significant reduction in the isogyric and isodesmic RMSDs (the surprisingly good result for the TAEs being presumably fortuitous). The recent "survival of the most transferable" $\omega$ B97X-V empirical range-separated hybrid, ${ }^{69}$ which has only a modest number of adjustable parameters but does employ the Vydrov-Van Voorhis dispersion treatment, appears to outperform both hybrids and fellow range-separated hybrids for the present problem.

The DSD-PBEP86-D3BJ double hybrid, on the other hand, holds its own well for the isodesmic reactions and yields excellent performance for the homodesmotic ones; for the isogyric reactions, it has a clear advantage over the older B2PLYP and B2GP-PLYP double hybrids. DSD-PBEPBE and DSD-PBEB95 likewise perform well. (Exploratory calculations with the very recently proposed DSD-PBEP86-NL ${ }^{102}$ functional yielded no further improvement, as a large portion of the dispersion is already captured by the double hybrid itself.)

Second-order Møller-Plesset perturbation theory near the basis set limit (in this case, MP2-F12/cc-pVQZ-F12) yields good performance for the (quasi)homodesmotic reactions, but clearly does not capture all the correlation effects for the isodesmic reactions.

Finally, it is useful to look at the performance of the composite methods that perform poorly for the atomization reactions. Table 6 gives these results for the CBS-QB3 and CBSAPNO methods. For both methods the (quasi)homodesmotic bond separation reactions represent improvements relative to the atomization reactions. Namely, for CBS-QB3 the RMSD drops from 4.2 to $2.8 \mathrm{kcal} \mathrm{mol}^{-1}$, whilst for CBS-APNO the RMSD drops from 2.5 to

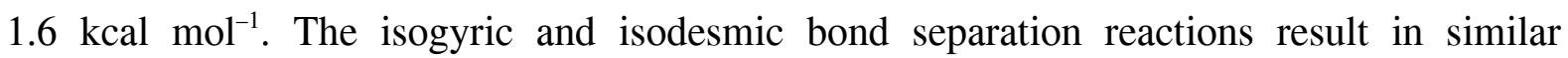
improvements for the CBS-APNO method, however, for CBS-QB3 they result in poor performance.

\section{Conclusions}

We have obtained benchmark total atomization energies and heats of formation at the relativistic, all-electron $\operatorname{CCSD}(\mathrm{T}) / \mathrm{CBS}$ limit for the platonic and prismatic $(\mathrm{CH})_{n}$ 
hydrocarbon cages by means of the W1-F12 and W2-F12 thermochemical protocols. Our best total atomization energies at $0 \mathrm{~K}\left(\mathrm{TAE}_{0}\right.$, Table 1) are: 755.99 (tetrahedrane), 1192.69 (triprismane), 1621.82 (cubane), 2088.38 (pentaprismane), 2586.01 (octahedrane), and 4393.55 (dodecahedrane) $\mathrm{kcal} \mathrm{mol}^{-1}$. An interesting observation is that these total atomization energies (and their components) vary almost linearly with the number of $\mathrm{CH}$ groups in the hydrocarbon cages. Our best $\Delta_{f} H^{\circ}{ }_{298}$ values are: 128.57 (tetrahedrane), 132.84 (triprismane), 144.78 (cubane), 119.42 (pentaprismane), 63.08 (octahedrane), and 20.18 (dodecahedrane) $\mathrm{kcal} \mathrm{mol}^{-1}$. Our W2-F12 heat of formation for cubane $\left(\Delta_{f} H^{\circ}{ }_{298}=144.8 \mathrm{kcal}\right.$ $\mathrm{mol}^{-1}$ ) suggests that the experimental gas-phase heat of formation from the NIST WebBook $\left(\Delta_{f} H^{\circ}{ }_{298}=142.7 \pm 1.2 \mathrm{kcal} \mathrm{mol}^{-1}\right)$ should be revised upwards by $\sim 2 \mathrm{kcal} \mathrm{mol}^{-1}$. These results are consistent with the recently published W1-F12 results of Agapito et al. ${ }^{86}$ Our heat of formation for dodecahedrane suggests that the reported 'semi-experimental' heat of formation of $22.4 \pm 1 \mathrm{kcal} \mathrm{mol}^{-1}$ should be revised downwards by $\sim 2 \mathrm{kcal} \mathrm{mol}^{-1}$.

Using our W1-F12 and W2-F12 benchmark total atomization energies, we evaluate the performance of a variety of composite $\mathrm{G} n$ and CBS procedures. We obtain the following RMSDs: 0.47 (G4), 0.64 (G3(MP2)B3), 0.90 (G4(MP2)), 1.31 (G3(MP2)), 1.39 (G3B3), 2.53 (CBS-APNO), 2.12 (G3), 2.88 (G4(MP2)-6X), and 4.17 (CBS-QB3) kcal mol ${ }^{-1}$. Thus, G4 gives excellent performance, and the G3(MP2)B3 and G4(MP2) procedures appear to offer the best performance-to-computational cost ratio.

Isodesmic and even homodesmotic reactions involving these species are surprisingly challenging targets for DFT calculations, due especially to large dispersion contributions (cf. also Ref. 103).

Supporting Information. Diagnostics indicating the importance of nondynamical correlation effects for the $(\mathrm{CH})_{n}$ hydrocarbon cages (Table $\left.\mathrm{S} 1\right)$; squared correlation coefficients $\left(\mathrm{R}^{2}\right)$ between the number of $\mathrm{CH}$ groups in the $(\mathrm{CH})_{n}$ hydrocarbon cages and the components of the TAEs in Table 1 (Table S2); molecular entropy corrections and Gibbs free energies of formation for the $(\mathrm{CH})_{n}$ hydrocarbon cages (Table S3); and B3LYP-D3BJ/Def2-TZVPP optimized geometries for all the species (Table S4).

Corresponding Author. E-Mail: amir.karton@uwa.edu.au (A.K.)

Acknowledgments. We gratefully acknowledge the generous allocation of computing time from the National Computational Infrastructure (NCI) National Facility, and system 
administration support provided by the Faculty of Science at UWA to the Linux cluster of the Karton group. AK is the recipient of an Australian Research Council (ARC) Discovery Early Career Researcher Award (projects number: DE140100311). JMLM is the Baroness Thatcher Professor of Chemistry at the Weizmann Institute of Science and acknowledges partial financial support from the Minerva Foundation, the Lise Meitner-Minerva Center for Computational Quantum Chemistry and the Helen and Martin Kimmel Center for Molecular Design. This study is dedicated to the late lamented Professor Paul von Ragué Schleyer who launched the fields of hydrocarbon cages and computational chemistry. ${ }^{1}$ 
TOC Graphic 1

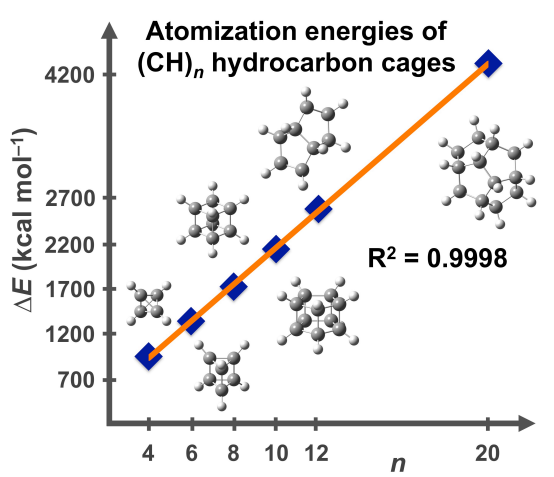




\section{References}

${ }^{1}$ P. von Ragué Schleyer, My Thirty Years in Hydrocarbon Cages: From Adamantane to Dodecahedrane. In: Cage Hydrocarbons; G. A. Olah, Ed.; Wiley, New York, 1990, Chapter ${ }^{2}$ Strained Hydrocarbons, H. Dodziuk, Ed.; Wiley-VCH, Weinheim, 2009.

3 G. Herzberg, Infrared and Raman Spectra of Polyatomic Molecules, Van Nostrand Reinhold, New York, 1945, p. 12.

${ }^{4}$ R. J. Ternansky, D. W. Balogh, L. A. Paquette, J. Am. Chem. Soc. 1982, 104, 4503.

${ }^{5}$ L. A. Paquette, Chem. Rev. 1989, 89, 1051.

${ }^{6}$ P. E. Eaton, T. W. Cole, J. Am. Chem. Soc. 1964, 86, 962; ibid 86, 3157.

${ }^{7}$ G. Maier, S. Pfriem, U. Schäfer, Angew. Chem. Int. Ed. 1978, 17, 520.

${ }^{8}$ T. J. Katz, N. Acton, J. Am. Chem. Soc. 1973, 95, 2738.

${ }^{9}$ P. E. Eaton, Y. S. Or, S. J. Branca, B. K. Ravi Shankar, Tetrahedron 1986, 42, 1621.

${ }^{10}$ C.-H. Lee, S. Liang, T. Haumann, R. Boese, A. de Meijere, Angew. Chem. Int. Ed. Engl. 1993, 32, 559 .

${ }^{11}$ A. de Meijere, C.-H. Lee, M. A. Kuznetsov, D. V. Gusev, S. I. Koshushkov, A. A. Fokin, P. R. Schreiner Chem. Eur. J. 2005, 11, 6175.

${ }^{12}$ A. Karton, J. M. L. Martin, J. Chem. Phys. 2012, 136, 124114.

${ }^{13}$ MOLPRO is a package of ab initio programs written by H.-J. Werner, P. J. Knowles, G. Knizia, F. R. Manby, M. Schütz, P. Celani, T. Korona, R. Lindh, A. Mitrushenkov, G. Rauhut, K. R. Shamasundar, T. B. Adler, R. D. Amos, A. Bernhardsson, A. Berning, D. L. Cooper, M. J. O. Deegan, A. J. Dobbyn, F. Eckert, E. Goll, C. Hampel, A. Hesselmann, G. Hetzer, T. Hrenar, G. Jansen, C. Köppl, Y. Liu, A. W. Lloyd, R. A. Mata, A. J. May, S. J. McNicholas, W. Meyer, M. E. Mura, A. Nicklaß, D. P. O'Neill, P. Palmieri, D. Peng, K. Pflüger, R. Pitzer, M. Reiher, T. Shiozaki, H. Stoll, A. J. Stone, R. Tarroni, T. Thorsteinsson, M. Wang. See: http:www.molpro.net.

${ }^{14}$ H.-J. Werner, P. J. Knowles, G. Knizia, F. R. Manby, M. Schütz, WIREs Comput. Mol. Sci. 2012, 2, 242.

15 J. M. L. Martin, G. de Oliveira, J. Chem. Phys. 1999, 111, 1843.

${ }^{16}$ A. Karton, E. Rabinovich, J. M. L. Martin, B. Ruscic, J. Chem. Phys. 2006, 125, 144108.

${ }^{17}$ A. Karton, S. Daon, J. M. L. Martin, Chem. Phys. Lett. 2011, 510, 165.

${ }^{18}$ C. Hättig, W. Klopper, A. Köhn, D. P. Tew, Chem. Rev. 2012, 112, 4.

${ }^{19}$ A. Karton, L.-J. Yu, M. K. Kesharwani, J. M. L. Martin, Theor. Chem. Acc. 2014, 133, 1483. 
${ }^{20}$ K. A. Peterson, T. B. Adler, H.-J. Werner, J. Chem. Phys. 2008, 128, 084102.

${ }^{21}$ A. Köhn, D. P. Tew, J. Chem. Phys. 2010, 132, 024101.

22 J. Noga, S. Kedžuch, J. Šimunek, J. Chem. Phys. 2007, 127, 034106.

${ }^{23}$ J. G. Hill, K. A. Peterson, G. Knizia, H.-J. Werner, J. Chem. Phys. 2009, 131, 194105.

${ }^{24}$ G. Knizia, T. B. Adler, H.-J. Werner, J. Chem. Phys. 2009, 130, 054104.

${ }^{25}$ G. Knizia, H.-J. Werner, J. Chem. Phys. 2008, 128, 154103.

${ }^{26}$ S. Ten-no, J. Noga, WIREs Comput. Mol. Sci. 2012, 2, 114.

${ }^{27}$ S. Ten-no, Chem. Phys. Lett. 2004, 398, 56.

${ }^{28}$ H.-J. Werner, T. B. Adler, F. R. Manby, J. Chem. Phys. 2007, 126, 164102.

${ }^{29}$ T. B. Adler, G. Knizia, H.-J. Werner, J. Chem. Phys. 2007, 127, 221106.

${ }^{30}$ K. A. Peterson, T. H. Dunning, J. Chem. Phys. 2002, 117, 10548.

${ }^{31}$ M. Douglas, N. M. Kroll, Ann. Phys. 1974, 82, 89.

${ }^{32}$ B. A. Hess, Phys. Rev. A 1986, 33, 3742.

${ }^{33}$ W. A. de Jong, R. J. Harrison, D. A. Dixon, J. Chem. Phys. 2001, 114, 48.

${ }^{34}$ T. H. Dunning, J. Chem. Phys. 1989, 90, 1007.

${ }^{35}$ R. A. Kendall, T. H. Dunning, Jr., R. J. Harrison, J. Chem. Phys. 1992, 96, 6796.

${ }^{36}$ C. E. Moore, Atomic energy levels as derived from the analysis of optical spectra, Volume

1, $\mathrm{H}$ to V; U.S. National Bureau of Standards Circular 467, COM-72-50282, U.S. Department of Commerce, National Technical Information Service: Washington, D.C., 1949. ${ }^{37}$ CFOUR, a quantum chemical program package written by J.F. Stanton, J. Gauss, M.E. Harding, P.G. Szalay with contributions from A.A. Auer, R.J. Bartlett, U. Benedikt, C. Berger, D.E. Bernholdt, Y.J. Bomble, L. Cheng, O. Christiansen, M. Heckert, O. Heun, C. Huber, T.-C. Jagau, D. Jonsson, J. Jusélius, K. Klein, W.J. Lauderdale, D.A. Matthews, T. Metzroth, L.A. Mück, D.P. O'Neill, D.R. Price, E. Prochnow, C. Puzzarini, K. Ruud, F. Schiffmann, W. Schwalbach, C. Simmons, S. Stopkowicz, A. Tajti, J. Vázquez, F. Wang, J.D. Watts and the integral packages MOLECULE (J. Almlöf and P.R. Taylor), PROPS (P.R. Taylor), ABACUS (T. Helgaker, H.J. Aa. Jensen, P. Jørgensen, and J. Olsen), and ECP routines by A. V. Mitin and C. van Wüllen. For the current version, see: http://www.cfour.de. 38 J. Gauss, A. Tajti, M. Kallay, J. F. Stanton, P. G. Szalay, J. Chem. Phys. 2006, 125, 144111.

${ }^{39}$ A. D. Becke, J. Chem. Phys. 1993, 98, 1372.

${ }^{40}$ C. Lee, W. Yang, and R. G. Parr, Phys. Rev. B 1988, 37, 785. 
${ }^{41}$ P. J. Stephens, F. J. Devlin, C. F. Chabalowski, M. J. Frisch, J. Phys. Chem. 1994, 98, 11623.

${ }^{42}$ F. Weigend, R. Ahlrichs, Phys. Chem. Chem. Phys. 2005, 7, 3297.

${ }^{43}$ S. Grimme, J. Antony, S. Ehrlich and H. Krieg, J. Chem. Phys. 2010, 132, 154104.

${ }^{44}$ S. Grimme, WIREs Comput. Mol. Sci. 2011, 1, 211.

${ }^{45}$ A. D. Becke, E. R. Johnson, J. Chem. Phys. 2005, 123, 154101.

${ }^{46}$ S. Grimme, S. Ehrlich, L. Goerigk, J. Comput. Chem. 2011, 32, 1456.

${ }^{47}$ M. K. Kesharwani, B. Brauer, and J. M. L. Martin, J. Phys. Chem. A 119, 1701 (2015)

${ }^{48}$ A. Karton, J.M.L. Martin, J. Chem. Phys. 2010, 133, 144102.

${ }^{49}$ L. A. Curtiss, P. C. Redfern, K. Raghavachari, WIREs Comput. Mol. Sci. 2011, 1, 810.

${ }^{50}$ L. A. Curtiss, P. C. Redfern, K. Raghavachari, J. Chem. Phys. 2007, 126, 084108.

${ }^{51}$ L. A. Curtiss, P. C. Redfern, K. Raghavachari, J. Chem. Phys. 2007, 127, 124105.

${ }^{52}$ B. Chan, J. Deng, L. Radom, J. Chem. Theory Comput. 2011, 7, 112.

${ }^{53}$ L. A. Curtiss, K. Raghavachari, P. C. Redfern, V. Rassolov, J. A. Pople, J. Chem. Phys. 1998, 109, 7764 .

${ }^{54}$ L. A. Curtiss, P. C. Redfern, K. Raghavachari, V. Rassolov, J. A. Pople, J. Chem. Phys. 1999, 110, 4703 .

${ }^{55}$ A. G. Baboul, L. A. Curtiss, P. C. Redfern, K. Raghavachari, J. Chem. Phys. 1999, 110, 7650 .

${ }^{56}$ J. W. Ochterski, G. A. Petersson, J. A. Montgomery, Jr. J. Chem. Phys. 1996, 104, 2598.

${ }^{57}$ J. A. Montgomery, Jr., M. J. Frisch, J. W. Ochterski, G. A. Petersson, J. Chem. Phys. 1999, 110, 2822; ibid 2000, 112, 6532.

${ }^{58}$ Gaussian 09, Revision D.01, M. J. Frisch, G. W. Trucks, H. B. Schlegel, G. E. Scuseria, M. A. Robb, J. R. Cheeseman, G. Scalmani, V. Barone, B. Mennucci, G. A. Petersson, H. Nakatsuji, M. Caricato, X. Li, H. P. Hratchian, A. F. Izmaylov, J. Bloino, G. Zheng, J. L. Sonnenberg, M. Hada, M. Ehara, K. Toyota, R. Fukuda, J. Hasegawa, M. Ishida, T. Nakajima, Y. Honda, O. Kitao, H. Nakai, T. Vreven, J. A. Montgomery, Jr., J. E. Peralta, F. Ogliaro, M. Bearpark, J. J. Heyd, E. Brothers, K. N. Kudin, V. N. Staroverov, R. Kobayashi, J. Normand, K. Raghavachari, A. Rendell, J. C. Burant, S. S. Iyengar, J. Tomasi, M. Cossi, N. Rega, J. M. Millam, M. Klene, J. E. Knox, J. B. Cross, V. Bakken, C. Adamo, J. Jaramillo, R. Gomperts, R. E. Stratmann, O. Yazyev, A. J. Austin, R. Cammi, C. Pomelli, J. W. Ochterski, R. L. Martin, K. Morokuma, V. G. Zakrzewski, G. A. Voth, P. Salvador, J. J. 
Dannenberg, S. Dapprich, A. D. Daniels, Ö. Farkas, J. B. Foresman, J. V. Ortiz, J. Cioslowski, and D. J. Fox, Gaussian, Inc., Wallingford CT, 2009.

${ }^{59}$ J. P. Perdew, K. Burke, M. Ernzerhof, Phys. Rev. Lett. 1996, 77, 3865.

${ }^{60}$ C. Adamo, V. Barone, J. Chem. Phys. 1999, 110, 6158.

${ }^{61}$ J. Tao, J. P. Perdew, V. Staroverov, and G. E. Scuseria, Phys. Rev. Lett. 2003, 91, 146401.

${ }^{62}$ S. Grimme, J. Phys. Chem. A 2005, 109, 3067.

${ }^{63}$ M. M. Quintal, A. Karton, M. A. Iron, A. D. Boese, and J. M. L. Martin, J. Phys. Chem. A 2006, 110, 709 .

${ }^{64}$ Y. Zhao, D. G. Truhlar, Theor. Chem. Acc. 2007, 120, 215.

${ }^{65}$ Y. Zhao and D. G. Truhlar, Acc. Chem. Res. 2008, 41, 157.

${ }^{66}$ J.-D. Chai, M. Head-Gordon, Phys. Chem. Chem. Phys. 2008, 10, 6615.

${ }^{67}$ Y. S. Lin, G. D. Li, S. P. Mao, J. D. Chai, J. Chem. Theory Comput. 2013, 9, 263.

${ }^{68}$ R. Peverati, D. G. Truhlar, J. Phys. Chem. Lett. 2011, 2, 2810.

${ }^{69}$ N. Mardirossian, M. Head-Gordon, Phys. Chem. Chem. Phys. 2014, 16, 9904.

${ }^{70}$ L. Goerigk, S. Grimme, WIREs Comput. Mol. Sci. 2014, 4, 576.

${ }^{71}$ S. Grimme, J. Chem. Phys. 2006, 124, 034108.

${ }^{72}$ A. Karton, A. Tarnopolsky, J.-F. Lamère, G. C. Schatz, J. M. L. Martin, J. Phys. Chem. A 2008, 112,12868 .

${ }^{73}$ S. Kozuch, J. M. L. Martin, Phys. Chem. Chem. Phys. 2011, 13, 20104.

${ }^{74}$ S. Kozuch, J. M. L. Martin, J. Comput. Chem. 2013, 34, 2327.

75 ORCA is a modern electronic structure program package written by F. Neese, with contributions from Ute Becker, Dmytro Bykov, Dmitry Ganyushin, Andreas Hansen, Robert Izsak, Dimitrios G. Liakos, Christian Kollmar, Simone Kossmann, Dimitrios A. Pantazis, Taras Petrenko, Christoph Reimann, Christoph Riplinger, Michael Roemelt, Barbara Sandhöfer, Igor Schapiro, Kantharuban Sivalingam, Frank Wennmohs, Boris Wezisla and contributions from our collaborators: Mihály Kállay, Stefan Grimme, Edward Valeev. Mülheim: Max Planck Institute for Chemical Energy Conversion, 2014.

${ }^{76}$ F. Neese, WIREs Comput. Mol. Sci. 2011, $2,73$.

${ }^{77}$ H. D. Beckhaus, C. Ruechardt, D. R. Lagerwall, L. A. Paquette, F. Wahl, H. Prinzbach, J. Am. Chem. Soc. 1994, 116, 11775.

${ }^{78}$ A. Karton, D. Gruzman, J. M. L. Martin, J. Phys. Chem. A 2009, 113, 8434.

${ }^{79}$ A. Karton, I. Kaminker, J.M.L. Martin, J. Phys. Chem. A 2009, 113, 7610. 
${ }^{80}$ A. Karton, B. Chan, K. Raghavachari and L. Radom, J. Phys. Chem. A 2013, 117, 1834.

${ }^{81}$ A. Tajti, P. G. Szalay, and J. Gauss, J. Chem. Phys. 2007, 127, 014102.

${ }^{82}$ B. Ruscic, R. E. Pinzon, M. L. Morton, G. von Laszewski, S. Bittner, S. G. Nijsure, K. A. Amin, M. Minkoff, A. F. Wagner, J. Phys. Chem. A 2004, 108, 9979.

${ }^{83}$ B. Ruscic, R. E. Pinzon, M. L. Morton, N. K. Srinivasan, M. C. Su, J. W. Sutherland, J. V. Michael, J. Phys. Chem. A 2006, 110, 6592.

${ }^{84}$ W. R. Stevens, B. Ruscic, T. Baer, J. Phys. Chem. A 2010, 114, 13134.

85 J. D. Cox, D. D. Wagman, V. A. Medvedev (1989) CODATA key values for thermodynamics, Hemisphere Publishing Corp., New York.

${ }^{86}$ F. Agapito, R. C. Santos, R. M. B. dos Santos, and J. A. Martinho Simões, J. Phys. Chem. A 2015, 119, 2998.

${ }^{87}$ B. D. Kybett, S. Carroll, P. Natalis, D. W. Bonnell, J. L. Margrave, J. L. Franklin, J. Am. Chem. Soc. 1966, 88, 626.

${ }^{88}$ S. W. Benson, Thermochemical Kinetics, 2nd ed., Wiley, New York (1976).

${ }^{89}$ A. Bashir-Hashemi, J. S. Chickos, W. Hanshaw, H. Zhao, B. S. Farivar, J. F. Liebman, Thermochimica Acta 2004, 424, 91.

${ }^{90}$ M. V. Roux, J. Z. Dávalos, P. Jiménez, R. Notario, O. Castanõ, J. S. Chickos, W. Hanshaw, H. Zhao, N. Rath, J. F. Liebman, B. S. Farivar, A. Bashir-Hashemi, J. Org. Chem. 2005, 70, 5461 .

${ }^{91}$ J. S. Chickos, J. Chem. Eng. Data 2010, 55, 1558.

92 Afeefy, H. Y.; Liebman, J. F.; Stein, S. E. Neutral Thermochemical Data. In NIST Chemistry WebBook, NIST Standard Reference Database Number 69; Linstrom, P. J., Mallard, W. G., Eds.; National Institute of Standards and Technology: Gaithersburg, MD; see http:// webbook.nist.gov.

${ }^{93}$ A. Karton, J. M. L. Martin, Mol. Phys. 2012, 110, 2477.

${ }^{94}$ A. Karton, A. Tarnopolsky and J. M. L. Martin, Mol. Phys. 2009, 107, 977.

${ }^{95}$ S. E. Wheeler, K. N. Houk, P. v. R. Schleyer, W. D. Allen, J. Am. Chem. Soc. 2009, 131, 2547.

${ }^{96}$ S. E. Wheeler, WIREs Comput. Mol. Sci. 2012, 2, 204.

${ }^{97}$ R. O. Ramabhadran, K. Raghavachari, Acc. Chem. Res. 2014, 47, 3596.

${ }^{98}$ R. O. Ramabhadran, K. Raghavachari, J. Chem. Theory Comput. 2011, 7, 2094.

${ }^{99}$ D. Barić, Z. B. Maksić, Theor. Chem. Acc. 2005, 114, 222. 
${ }^{100}$ O. Vydrov, T. Van Voorhis, J. Chem. Phys. 2010, 133, 244103.

${ }^{101}$ W. Hujo, S. Grimme, J. Chem. Theor. Comput. 2011, 7, 3866.

${ }^{102}$ F. Yu, J. Chem. Theor. Comput. 2014, 10, 4400.

${ }^{103}$ M. D. Wodrich, C. Corminboeuf, P. R. Schreiner, A. A. Fokin, P. v. R. Schleyer, Org. Lett. 2006, 9, 1851. 